\title{
Maternidad y lesbianismo en cuerpo de mujer chilena
}

\author{
Karen Atala ${ }^{1}$ \\ Abogada \\ jk.atala@gmail.com \\ Una sociedad lesbiana \\ destruye el hecho artificial (social) \\ que constituye a las mujeres \\ como "grupo natural". \\ Monique Wittig
}

La Excma. Corte Suprema de Chile, con fecha 31 de mayo de 2004, resolvió en una sentencia sobre juicio de tuición de menores, que había inhabilidad materna de criar y educar a mis hijas, basándose en "desde que la madre empezó a convivir en el hogar con su pareja homosexual y a que las niñas podrían ser objeto de discriminación social derivada de este hecho", para luego en otro considerando del fallo exponer "que la madre de las menores de autos, al tomar la decisión de explicitar su condición homosexual, como puede hacerlo libremente toda persona en el ámbito de sus derechos personalísimos en el género sexual, sin merecer por ello reprobación o reproche jurídico alguno, ha antepuesto sus propios intereses, postergando los de sus hijas, especialmente al iniciar una convivencia con su pareja homosexual en el mismo hogar en que lleva a efecto la crianza y cuidado de sus hijas", "la eventual confusión de roles sexuales que puede producírseles por la carencia en el hogar de un padre de sexo masculino" y "dicha situación situará a las menores López Atala a un estado de vulnerabilidad en su medio social... exponiéndolas a ser objeto de aislamiento y discriminación" ${ }^{2}$. 
Ahora nos encontramos en un nuevo escenario, la Corte Interamericana de Derechos Humanos ha determinado que hubo violación por parte del Estado chileno, a través de su Corte Suprema, toda vez que, según los diversos tratados internacionales y los estándares establecidos en el Tribunal Europeo y los Organismos de Naciones Unidas, la Corte Interamericana deja establecido que la orientación sexual y la identidad de género de las personas son categorías protegidas por la Convención al interpretarse de manera progresiva "otra condición social" establecida en su Artículo 1.1. y determina que "Un derecho que les está reconocido a las personas no puede ser negado o restringido a nadie y bajo ninguna circunstancia con base en su orientación sexual"

En términos generales, las Cortes Supremas de un país constituyen el máximo instrumento de la dominación ideológica y simbólica del discurso dominante de dicho país, asimismo, expresan los valores religiosos (ya sea la iglesia católica, protestante, musulmana $\mathrm{u}$ otra) y a la oligarquía gobernante (ya sea capitalista, socialista, etc.). En el caso particular, esta sentencia nacional importa un deber ser al expresar una verdad universal y totalizante y excluyente de las diferencias del sistema sexo/género y principalmente de las diferentes prácticas sexuales, legitimadas como actos de habla que, en forma de sentencias, son emitidos desde el discurso jurídico de la ley.

En este sentido, en Chile no existe una institucionalidad formal en contra del homosexual, pero se discurre en la llamada "heteronormatividad", es decir, el conjunto de normas legales, instituciones sociales y prácticas jurídico-administrativas que tienen una matriz heterosexual, que les da sentido y valor, sirviendo para inspirar, interpretar o valorar cualquier tipo de situación fáctica y cuyo reconocimiento en el campo jurídico se precisa. La heteronormatividad impera en la legislación chilena por mandato cultural.

En la Carta Fundamental chilena, en su Artículo $1^{\circ}$, se establece que "Las personas nacen libres e iguales en dignidad y derechos. La familia es el núcleo fundamental de la sociedad... es deber del Estado... dar protección a la población y a la familia, proponer el fortalecimiento de ésta...". En su Artículo 5 señala "El ejercicio de la soberanía reconoce como limitación el respeto a los derechos esenciales que emanan de la naturaleza humana. Es deber de los órganos del Estado respetar y promover tales derechos, garantizados por esta Constitución, así como los tratados internacionales 
ratificados por Chile y que se encuentren vigentes" 4 . Por su parte, la Ley 19.947, sobre Matrimonio Civil, en su Artículo Primero establece "La familia es el núcleo fundamental de la sociedad. El matrimonio es la base principal de la familia" ${ }^{5}$, para luego el Código Civil definir al matrimonio como "un contrato solemne por el cual un hombre y una mujer se unen..."6.

Así, el legislador no definió el concepto de familia, pero al establecer que el matrimonio heterosexual es la base principal de ella, simbólicamente le está dando un carácter unívoco y excluyente, aunque también en cierta medida se permitió el concubinato (o unión básica entre un hombre y una mujer sin mediar matrimonio) como pacto sexual, heteronormativo y reconocerle la posibilidad de constituir una familia y, por ende, de parentesco ilegítimo. Con los avances sociales de mediados del siglo XX, a la par de la suscripción de diversos tratados internacionales sobre igualdad de derechos, se comienza a igualar los derechos de la familia "ilegítima" frente a la legítima, principalmente en materia de sucesiones y derechos sociales.

De más está decir que el legislador no define el concepto de familia por una razón lógica. Esta es una institución cambiante según los tiempos, las circunstancias económicas, sociales y morales de un país. En el contexto histórico de don Andrés Bello -redactor del Código Civil que data de 1855- formaban parte de la familia los criados y sirvientes de confianza; así lo explicitó en un artículo sobre el contrato de Uso y Habitación en el Artículo 815 de dicho Código: "La familia comprende al cónyuge y los hijos; tanto los que existen al momento de la constitución -del contrato-, como los que sobrevienen después, y esto aun cuando el usuario o el habitador no esté casado, ni haya reconocido hijo alguno a la fecha de su constitución.

Comprende asimismo el número de sirvientes necesarios para la familia.

Comprende, además, las personas que a la misma fecha vivían con el habitador o usuario y a costa de éstos; y las personas a quienes éstos deben alimentos", pues ello era absolutamente normal en el siglo XIX. Ahora, por ejemplo, nos parecería absurdo incluso el concepto de "sirvientes". Esta norma está absolutamente vigente hoy en día, aunque jurídicamente pueda estar en desuso.

Otra señal indiciaria de familia nos aporta nuestro Código Penal de 1879 -que nos rige hasta hoy- a propósito del delito de amenazas, en su Artículo 296 inciso final; "Para los efectos de este artículo se 
entiende por familia el cónyuge, los parientes en la línea recta de consanguinidad o afinidad legítima, los padres e hijos naturales y la descendencia legítima de éstos, los hijos ilegítimos reconocidos y los colaterales hasta el tercer grado de consanguinidad o afinidad legítimas"

Dadas así las cosas, no se ha definido por el legislador el concepto de familia, pero del conjunto de normas señaladas se infieren las características que ésta debe reunir:

-Existencia de una unión matrimonial,

-Heterosexualidad de los cónyuges constituyentes,

-Capacidad de generar descendencia biológica y extensiva a la filiación por afinidad (que remite de nuevo al vínculo matrimonial, cerrando el círculo).

-Es una institución de élite (los criados no tienen familia propia, sino en cuanto acceden a la de sus amos).

Estas son las directrices legislativas vigentes que nos dan los indicios que se deben considerar en el concepto de familia; ésta sólo se origina a través de la heteronormatividad, elevándose esta última a la categoría jurídica de "núcleo fundamental" del entramado jurídico. De esta pirámide valórica se arrastra hasta hoy día la diferencia entre los hijos, "matrimoniales vs. no matrimoniales". Las normas que regulan el régimen patrimonial del matrimonio, la filiación y la sucesión han debido ser objeto de numerosas modificaciones en estos ciento sesenta años.

Pero llamo la atención sobre el hecho que la propia Ley de Matrimonio Civil y la Constitución Política de la República se refieren a que la familia es el "núcleo fundamental" de la sociedad. Sin embargo, dicho enunciado no es neutro, porque la familia es una forma de organización social, que surgió históricamente para abordar las prácticas de proveerse el alimento (unidad económica de sustento), y con las diversas concepciones sociales, el ideologema familiar implícito que inspiró a nuestros cuerpos de leyes, apunta a la familia como núcleo económico burgués en una sociedad capitalista, inspirada en la estética romántica. De ahí que las concepciones que se le derivan (matrimonio, filiación, herencias, etc.) surgen de dicha concepción familiar. Lo importante son las personas, éstas son la base fundamental de la sociedad, sin personas no hay uniones, alianzas que adquieran el carácter de familia ${ }^{8}$. 
Ahora, junto a la familia chilena y los roles asignados según el sexo, entra la valoración de la mujer madre dentro del ideologema del catolicismo; es decir, modelo de virgen María o mariano; mater dolorosa, sufriente, abnegada, postergada por la crianza de sus hijos. Por el solo hecho de su enunciación, entonces, el contrato matrimonial impone a sus participantes, y en especial al sujeto femenino, los roles recién mencionados.

En síntesis, como emisores de la cultural dominante, los jueces representan parte del imaginario conservador del pueblo latinoamericano con la figura de la Virgen María y sus múltiples representaciones y ejemplos a seguir por las mujeres y madres latinoamericanas. En efecto, ellos, como detentadores de las estrategias micropolíticas del poder, moralizan a través de su sentencia del año 2004 que, la vida privada de la demandada, por afectar su vida al ideologema de familia frente al Estado regulador. Por otra parte, la institución matrimonial siempre ha sido considerada un espacio público, normado por las leyes del Estado y también bajo los efectos de su intromisión en forma de valores sociales, discursos y tecnologías represivas aplicadas por otras instituciones del ámbito estatal, como la escuela y el trabajo, que norman no sólo sus procedimientos específicos, sino también los horarios, conductas, costumbres, etc., al interior del matrimonio. Esto nos recuerda el importante concepto de "capital cultural" propuesto por Pierre Bourdieu, como una manera de explicar que la reproducción social no sólo funciona en base a las condiciones económicas y de clase, sino que éstas, además, imponen particulares condiciones de reproducción de un determinado capital cultural de clase.

Siguiendo la célebre afirmación de Simone de Beauvoir, que "no se nace mujer, llega una a serlo", a partir de la cual se han desarrollado las teoría del género, cito a Judith Butler, quien ha definido el género como un sistema de reglas, convenciones, normas sociales y prácticas institucionales que producen performativamente al sujeto que pretenden describir, así, esta autora no identifica el género como una esencia ni como una verdad psicológica, sino como una práctica discursiva y corporal/ preformativa, a través de la cual el sujeto adquiere inteligibilidad social y reconocimiento político.

Existen distintas formas de representación de lo femenino. Elisabeth Roudinesco señala magistralmente que a raíz de la diferencia 
sexual, si se reduce al binarismo masculino / femenino hombres / mujeres, se puede plantear en términos de una representación complementaria, en este caso, la mujer pasa a ser un alter ego del hombre, o se inferioriza a la mujer, haciéndola caer en una suerte de zoológico (monstruo, andrógino, lesbiana, prostituta); o se le idealiza y se convierte a la mujer en un suplemento heterogéneo al orden simbólico: la loca, la mística, la virgen. La autora trata de explicar cómo a raíz de estas distintas interpretaciones de la femineidad se dedujeron las posiciones de poder, sometimiento, exclusión o complementariedad de las mujeres dentro de la sociedad. Estas categorizaciones de las mujeres inevitablemente nos derivan, según la autora, a la posición de las mujeres en la familia de los Labdácidas (Edipo será el mito fundante del orden social familiar burgués), condenando a las mujeres a no encontrar su lugar jamás, salvo bajo el signo de la locura, el asesinato y la mancha. Luego, a partir de esta maternidad se establece que el sexo es matrimonial, monogámico, heterosexual y reproductivo.

Es esta condición de sexualidad reproductiva y de maternidad, que en términos de producción, denominada "división sexual del trabajo" siguiendo a Marx, necesariamente tiene cabida en el orden heterosexual. En efecto, lo que constituye a una mujer en una relación social específica deriva de su rol respecto de un hombre, de las relaciones económicas, de las obligaciones personales, obligaciones físicas que se derivan, por ejemplo, de su condición de soltera, casada, viuda, divorciada, subordinada a otro.

En las sociedad post capitalistas, en lo que la teórica y activista Beatriz Preciado ha denominado sociedades farmacopornográficas, "el género del siglo XXI funciona como un dispositivo abstracto de subjetivación técnica; se pega, se corta, se inyecta, se injerta, se digitaliza, se vende, se compra, etc., de manera que el régimen farmacopornográfico de la sexualidad no puede funcionar sin la circulación de una enorme cantidad de flujos semioticotécnicos; flujos de hormonas, de digitalización de siliconas, de representación, etc." ${ }^{\prime 9}$

Sobre la teoría marxista de la división sexual del trabajo, Preciado señala que a la luz de la farmacopornografía, el concepto de división sexual de trabajo se refiere a la división reproductiva de la especie, estableciéndose una segmentación estructural entre cuerpos con úteros capaces de llevar a término el desarrollo de un feto viable 
y cuerpos sin útero o con útero, pero sin posibilidad de gestación. Por ello es más pertinente hablar de "división gestacional del trabajo" para referirse a la segmentación de cuerpos derivada de la capacidad de gestar in utero.

Por otro lado, el concepto de división sexual del trabajo, por defecto, es de carácter normativamente heterosexual, dando por sentado que la reproducción heterosexual es la única natural. Con la invención de la píldora anticonceptiva, al separar heterosexualidad y reproducción, se viene en dejar al descubierto que "no todo trabajo de reproducción implica un trabajo sexual, ni todo trabajo sexual implica un trabajo reproductor". Por lo tanto, la división del trabajo sexual no depende de una cualidad natural sino de una programación de especialización técnica del cuerpo, una bioprogramación. Para concluir, de este modo, que en la sociedad farmacopornográfica (o postfordista), las mujeres hacen en esta sociedad el trabajo del cuidado del cuerpo, tanto de los hombres como de las otras mujeres heterosexuales, siendo esto en definitiva lo que se oculta bajo la noción marxista de división sexual del trabajo.

Volviendo a nuestra realidad de país, la "familia" según estadística oficial emanada del Servicio Nacional de la Mujer, arrojó para el año 2003 un porcentaje sobre hijos nacidos dentro del matrimonio $(44,44 \%)$ versus los que nacían fuera de él $(55,56 \%)^{10}$. Es decir, en la realidad chilena, más del $50 \%$ de los hijos nace fuera del matrimonio y casi el mismo porcentaje lo constituyen las familias monoparentales, donde la madre es quien cría sola o con escasa ayuda del progenitor, a sus hijos. Todo ello sumado al escaso número de matrimonios contraídos versus la cantidad de personas que prefieren vivir bajo la modalidad del concubinato. Es decir, estos fenómenos sociales ya nos están dando cuenta en Chile de la crisis del concepto de familia idealizada, donde existe una madre y un padre unidos bajo contrato matrimonial, y diferenciación de roles e hijos. A este fenómeno social le podemos agregamos, además, la posibilidad de la reproducción asistida, en que el donante del esperma puede ser anónimo, al igual que la donante de óvulos, y la figura del arriendo de útero.

Bástenos con leer a Ann Cadoret en su libro Padres como los demás. Homosexualidad y parentesco, en el cual se plantean muchas de las posibilidades de acceder a la procreación: "La técnica puede amparar a la naturaleza... La procreación, esta mezcla de gametos masculinos y 
femeninos, puede realizarse artificialmente, sin encuentro sexual entre un hombre y una mujer, ya que la técnica puede sustituir el intercambio 'natural' de los dos sexos. Con el fin de enmarcar esta evolución, se investiga indefinidamente en el ámbito de la ética de la persona para determinar el lugar que corresponde al individuo en el mundo actual y asociarle una concepción de familia, pues la procreación asistida plantea múltiples cuestiones... La temática del individuo, que recurre a nociones como vida, humanidad y persona, respaldada por la de dominio técnico, que pivota sobre las relaciones entre naturaleza, ciencia y progreso técnico, se proyecta sobre la temática de la constitución familiar para desglosar los tres términos de esta última: sexualidad, conyugalidad y parentesco" ${ }^{11}$. O a Elisabeth Roudinesco, La Familia en desorden ${ }^{12}$; quien plantea que el matrimonio, como una institución definida por las posturas tradicionales jurídicas, va cayendo por sus propias contradicciones; y no sólo la institución matrimonial, sino también otras que se le derivan, como la presunción de paternidad legal, la acción de reclamación de estado civil de hijo o hija matrimonial, el derecho de sucesión, etc.

La existencia de las familias lesbianas y gays implica una redefinición del parentesco y creación de nuevas formas de paternidad, que ahora, por mandato de la Corte Interamericana de Derechos Humanos a raíz del Caso Atala, necesariamente abrirán nuevos paradigmas interpretatorios, donde autores como Judith Butler nos servirán de grandes referentes. Ella ha señalado que "parentesco (es) una serie de prácticas que instituyen relaciones de diversos tipos que negocian la reproducción de la vida y las exigencias de la muerte, [...] las prácticas del parentesco s[on] aquellas que surgen del abordaje de formas fundamentales de dependencia humana, que pueden comprender nacimientos, crianza de niños, relaciones de apoyo y dependencia emocional, lazos generacionales, enfermedad y muerte (para nombrar algunas)"13.

Ahora en Chile, se está dando sentido a las demandas de igualdad ante la ley, encontrándose en tramitación la Ley Antidiscriminatoria (que lleva siete años en el Congreso), no exenta de duros debates valóricos entre los actores conservadores, religiosos, liberales, etc. Por otra parte, se han enviado proyectos sobre Pactos de Unión Civil (PUC) o Acuerdo de Vida en Pareja (AVP), que desde la mirada hegemónica buscan dar reconocimiento legal a situaciones de hecho, las convivencias homosexuales. 
Sin embargo, la heteronormatividad sigue imponiéndose. En efecto, los heterosexuales tienen derecho al matrimonio y al divorcio, y de aprobarse algunos de los proyectos que se encuentran en tramitación en el Congreso, los heterosexuales que no crean en el matrimonio, podrán contraer un pacto civil que sólo les regula sus bienes patrimoniales, dado que la descendencia aunque sea "no matrimonial" ya se encuentra regulada en el Código Civil y diversas leyes, por ende, los PUC o AVP sólo vendrían a mejorarles sus estatutos privilegiados. Y para los gays, las lesbianas, los transexuales veremos nuestra realidad afectiva y familiar reducida a una simple condición jurídica de "pactante". También se es pactante en un contrato de compraventa, arriendo, trabajo, prestación de servicios, etc. Este vocablo "pactante" es tan genérico y amplio que produce la desrealización del Otro, pues sólo importa un reconocimiento a la "comunidad de bienes", pero al no enunciarlo expresamente, silencia en su discurso todo lo referente a la ética del cuidado que se da en la pareja. No se pronuncia sobre los vínculos familiares que se forman. Tampoco se refiere a la diversidad familiar. ¿Cómo llamarán los hijos biológicos de una mujer a la compañera de vida de su madre? ¿Qué derechos tendrá la co-madre, frente a los hijos de su pareja si ésta muere? ¿o en caso de separación? Son muchas las situaciones reales, del diario vivir, que este proyecto de ley no contempla ni regula, al contrario, se invisibiliza una vez más la realidad ético afectiva y familiar conformada por la comunidad LGTBI ${ }^{14}$.

En la cúpula del poder chileno, representada por los legisladores, persiste el concepto de "familia tradicional" que es merecedora de todos los derechos. ¿Qué es una familia tradicional? ¿Por qué se dice que no afecta los valores de la familia tradicional? ¿Cuáles serían esos "valores"? Ahora, el discurso legal del Congreso Nacional sólo valida la heteronormatividad.

Ante la legislación chilena, representada por el Ejecutivo, Legislativo y Judicial, nuestra comunidad LGTBI es deshumanizada, desprovista de las características que la hacen reconocible, limitándose su humanidad, su constitución como sujeto en un mínimo, incuantificable, innombrable, abyecto, incluso ahora, en circunstancias que la Sentencia de la Corte Interamericana en el Caso Atala constituye el primer paso hacia la construcción de una sociedad diferente, inclusiva y digna. Es cosa de avanzar. 


\section{Notas}

1 Abogada, jueza, lesbiana y madre. Parte en la demanda de la Comisión Interamericana de Derechos Humanos contra el Estado Chileno ante la Corte Interamericana de Derechos Humanos, por la pérdida de la custodia de sus hijas en razón de estimarse que su familia lesbiana no era compatible en el concepto familiar tradicional chileno.

2 Corte Suprema de Chile, sentencia en causa de Queja Disciplinaria caratulada "López con Atala", 31 de mayo de 2004.

3 Párrafo 93. De la Sentenciade la Corte Interamericana de Derechos Humanos Caso Atala Riffo y Niñas Vs. Chile. Sentencia de 24 de febrero de 2012.

4 Constitución Política de la República de Chile. Santiago. Editorial Lexis Nexis, Quinta edición, actualizada al 17 de enero de 2005.

5 Ley 19.947, publicada en el Diario Oficial de la República de Chile el 17 de mayo de 2005.

6 Código Civil Chileno. Santiago: Editorial Jurídica de Chile, $16^{\circ}$ Edición, actualizado a 20 octubre de 2004.

7 Código Penal Chileno. Santiago: Editorial Jurídica de Chile, 19a Edición, año 2004. Es curioso como esta norma no fue modificada por la Ley $\mathrm{N}^{\circ} 19.585$ sobre Filiaciones del 26 de octubre de 1998, que estableció dos categorías de hijos; matrimoniales y no matrimoniales, eliminando la categoría de hijos legítimos, naturales e ilegítimos por ser atentatoria al artículo $1^{\circ}$ de la C.P.R.

8 Un interesante trabajo que aborda las diferentes concepciones de familia, desde la antropología, es el de Florencia Herrera, "Construir familia: la perspectiva de gays y lesbianas", en Temas Sociales, Boletín No 48 y 49, 2004, de Sur Corporación de Estudios Sociales y Educación. Asimismo, tiene una importante aportación bibliográfica sobre el tema.

9 Beatriz Preciado. Testo Yonqui. Madrid: Espasa Calpe, 2008.

10 Ver www.sernam.cl/basemujer/index.htm

11 Ann Cadoret. Padres como los demás. Homosexualidad y parentesco. Barcelona: Ed. Gedisa, $1^{\text {a} E d i c i o ́ n, ~ 2003, ~ 113-114 . ~}$

12 Elisabeth Roudinesco. La Familia en desorden. Argentina: Fondo de Cultura Económica y Social, 2003.

13 Judith Butler. Deshacer el Género. Barcelona: Paidos, 2006.

14 Sigla para denominar a las personas Lesbianas, Gays, Bisexuales, Transexuales, Transgéneros e Intersexuales. 